Published in: Radiation Measurements 59 (2013) 201-204.

DOI: http://dx.doi.org/10.1016/j.radmeas.2013.07.003

\title{
EXPERIMENTAL TECHNIQUE TO MEASURE THORON GENERATION RATE OF BUILDING MATERIAL SAMPLES USING RAD7 DETECTOR
}

\author{
I. Csige ${ }^{1}$, Zs. Szabó ${ }^{2,3, *}$, Cs. Szabó ${ }^{2}$ \\ ${ }^{1}$ Institute for Nuclear Research, Hungarian Academy of Sciences, H-4001 Debrecen, P.O. \\ Box 51, Hungary \\ ${ }^{2}$ Lithosphere Fluid Research Lab, Department of Petrology and Geochemistry, Eötvös \\ University, Pázmány P. s. 1/C, H-1117 Budapest, Hungary \\ ${ }^{3}$ Centre for Energy Research, Hungarian Academy of Sciences, H-1525 Budapest, 114., P.O. \\ Box 49, Hungary \\ *Corresponding author \\ E-mail: zsszabo86@gmail.com, szabo.zsuzsanna@energia.mta.hu
}

\section{Abstract}

Thoron $\left({ }^{220} \mathrm{Rn}\right)$ is the second most abundant radon isotope in our living environment. In some dwellings it is present in significant amount which calls for its identification and remediation. Indoor thoron originates mainly from building materials. In this work we have developed and tested an experimental technique to measure thoron generation rate in building material samples using RAD7 radon-thoron detector. The mathematical model of the measurement technique provides the thoron concentration response of RAD7 as a function of the sample thickness. For experimental validation of the technique an adobe building material sample was selected for measuring the thoron concentration at nineteen different sample thicknesses. Fitting the parameters of the model to the measurement results, both the generation rate and the diffusion length of thoron was estimated. We have also determined the optimal sample thickness for estimating the thoron generation rate from a single measurement. 


\section{Symbols}

$A$ : cross-sectional area of the cylindrical sample holder $\left(\mathrm{m}^{2}\right)$

$C$ : thoron activity concentration $\left(\mathrm{Bq} \mathrm{m}^{-3}\right)$

$D$ : diffusion coefficient in the sample $\left(\mathrm{m}^{2} \mathrm{~s}^{-1}\right)$

$G$ : thoron generation rate in the sample $\left(\mathrm{Bq} \mathrm{m}^{-3} \mathrm{~s}^{-1}\right)$

$H$ : height of the sample holder (m)

$h$ : thickness of the sample (m)

$j$ : activity flux of thoron ( $\left.\mathrm{Bq} \mathrm{m}^{-2} \mathrm{~s}^{-1}\right)$

L: partition coefficient of thoron between water and air phase (-)

m: water saturation (-)

$q$ : air flow rate induced by the RAD7 radon-thoron detector $\left(\mathrm{m}^{3} \mathrm{~s}^{-1}\right)$

$t$ : time (s)

$V$ : rest of the volume of the sample holder above the sample $\left(\mathrm{m}^{3}\right)$

$z$ : elevation $(\mathrm{m})$

$z_{d}$ : diffusion length of thoron in the sample (m)

$\beta$ : partition corrected porosity (-)

$\varepsilon$ : porosity (-)

$\gamma:$ reciprocate of the diffusion length $\left(\mathrm{m}^{-1}\right)$

$\lambda$ : decay constant of thoron $\left(\mathrm{s}^{-1}\right)$

\section{Introduction}

The only gaseous isotope of the ${ }^{232} \mathrm{Th}$ decay chain is ${ }^{220} \mathrm{Rn}$ (thoron) which, similarly to ${ }^{222} \mathrm{Rn}$ (radon) in the ${ }^{238} \mathrm{U}$ decay chain, is omnipresent in our living environment. Its contribution to the average effective dose to people from natural background radiation is estimated to be about an order of magnitude smaller than that of radon (UNSCEAR, 2000) due to its short half-life (55.6 s). However, several studies (e.g. Sciocchetti et al., 1992; Németh et al., 2005; Shang et al., 2005; Yamada et al., 2005; Yonehara et al., 2005) show high thoron activity concentrations in some dwellings. In most of these cases thoron originates from building materials made by soil and mud, like in case of adobe dwellings in Hungary. Significant amount of thoron can enter buildings from this type of walls; hence the measurement of thoron generation rate in building material samples can be highly useful to characterize radiation safety of these materials (Tuccimei et al., 2006). In one of our ongoing 
study, in which tens of Hungarian adobe building material samples are tested for radiation safety purposes (e.g. Szabó et al., 2013), the development of an appropriate experimental method to measure thoron generation rate became necessary. Ujić et al. (2008) published a method using SSNTD detectors, in this paper we present an experimental technique developed for this purpose using RAD7 radon-thoron detector.

\section{Experimental setup}

The schematic view of the experimental setup is shown on Fig.1. It consists of a cylindrical shape aluminum sample holder with cross-sectional area of $A=38.5 \mathrm{~cm}^{2}$ and height of $H=9.5 \mathrm{~cm}$; plastic tubing; a gas-drying unit filled with desiccant $\left(\mathrm{CaSO}_{4}\right.$ with $3 \%$ $\mathrm{CoCl}_{2}$ as indicator); an aerosol filter and a RAD7 radon-thoron detector (Durridge Co., 2013). All connections are insulated by parafilm (product of the Pechiney Plastic Packaging Company). Unlike radon, thoron cannot leak in significant amount from the experimental setup due to its very short half-life.

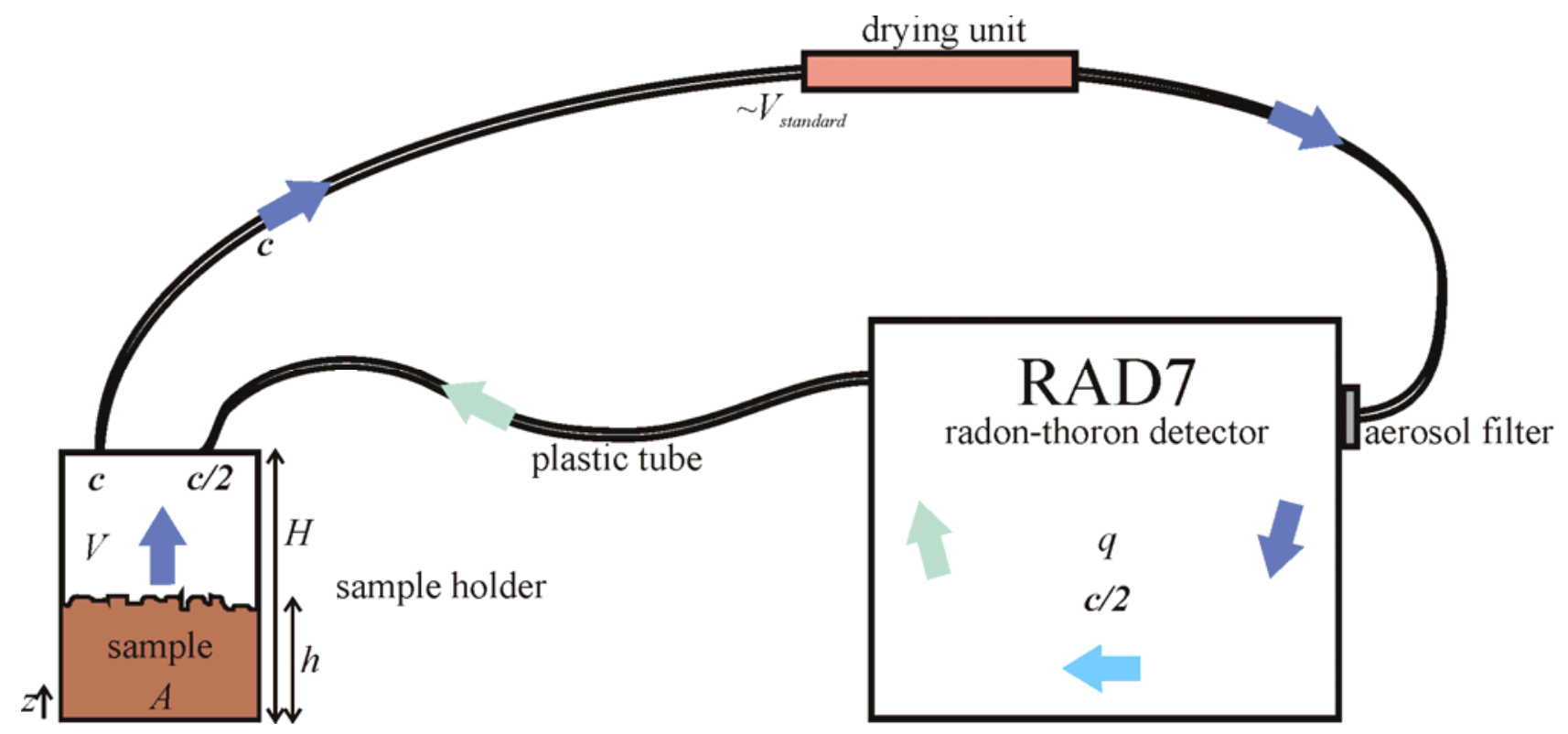

Fig.1.: Schematic representation of the experimental setup. The tone of arrows together with $c$ and $c / 2$ represent the decreasing thoron concentration along the air flow's path. The measurable thoron concentration in the air above the sample (c) depends on the sample thickness ( $h$ ) and the properties of the sample. The sample holder has a height indicated by $H$ and a cross-sectional area indicated by A. V means the volume above the sample in the sample holder and $q$ is the air flow rate induced by the pump of the RAD7 radon-thoron detector (Durridge Co. Inc., 2000). 
The cylindrical shape sample with a thickness of $h$ occupies the bottom part of the sample holder. Thoron is generated by the decay of ${ }^{224} \mathrm{Ra}$ atoms present in the solid phase of the sample. Part of these atoms is emanated into the pore space of the sample. Thoron generation rate $(G)$ in the sample is defined as the activity of thoron that is emanated into the pore space of unit bulk volume of the sample in unit time $\left(\mathrm{Bq} \mathrm{m} \mathrm{s}^{-3}\right)$. We assume that the only transport process that results in thoron exhalation from the sample is molecular diffusion. Thoron that diffuses into the air-filled part of the sample holder (with volume: $V=A(H-$ h)) is sampled continuously by a RAD7 detector. The RAD7 detector induces a stable air circulation through the system at the calibrated rate of $q=11 \mathrm{~cm}^{3} \mathrm{~s}^{-1}$ (Durridge Co., 2013). This flow rate is high enough to ensure that the air is mixed sufficiently and thoron is distributed uniformly both in the air-filled space in the sample holder and in the measuring chamber of the RAD7 detector.

Under steady state conditions the RAD7 detector provides and displays the activity concentration of thoron that is sampled at the end of its inlet tubing. In this closed system, thoron concentration grows to within $3 \%$ of its secular equilibrium state in about five minutes. The RAD7 factory calibration for thoron is based on a standard RAD7 inlet filter, a 3-foot long, 3/16 inch inner diameter vinyl hose, and a small (6 inch) drying tube. Because of the short half-life of thoron, the volume of the measurement chamber $\left(750 \mathrm{~cm}^{3}\right)$ and the calibrated flow rate, the activity concentration of thoron in the detector cell is estimated to be about half of its value at the sampling point. This decay mainly happens in the RAD7, and it is negligible in the plastic tubes and the gas-drying unit. For these reasons, the RAD7 displays the double of the concentration that is in its detector cell. As a further consequence, the thoron concentration of air that returns into the air volume of the sample holder in our experimental setup is also half of the concentration that is found there under steady state conditions. This causes significant attenuation which is taken into account in our model calculation.

\section{Model}

In this section we derive the formula to calculate the thoron concentration $\left(C,\left(\mathrm{Bqm}^{-3}\right)\right)$ in the air-filled volume of the sample holder, which is measured and displayed by the RAD7 detector in our experimental setup. Because of the cylindrical symmetry of the sample holder, thoron concentration in the pore space of the sample, $C(z)$, depends only on the elevation coordinate $(z)$. Diffusion of thoron in the sample is described by the steady state transport equation: 


$$
\frac{d^{2} C(z)}{d z^{2}}=\frac{1}{D}(-G+\lambda \beta C(z))
$$

where $D$ is the thoron diffusion coefficient in the sample $\left(\mathrm{m}^{2} \mathrm{~s}^{-1}\right), \lambda$ is the decay constant of thoron $\left(0.0125 \mathrm{~s}^{-1}\right)$ and $\beta=(1-m+L m) \varepsilon$ is the partition corrected porosity taking into account porosity $(\varepsilon)$, water saturation $(m)$ and the partition coefficient of thoron between water and air phase $(L)$ (Andersen, 1992). We apply no flux boundary condition on the bottom of the sample container, i.e. $\left.\frac{d C(z)}{d z}\right|_{z=0}=0$. The boundary condition on the top surface of the sample states that the activity concentration of thoron in the pore space of the sample equals that in the air-filled volume of the sample holder, $C(z=h)=C$. The rate of change of thoron activity concentration in the air-filled volume of the sample holder is described by the following differential equations, which however, under steady state conditions, reduces to an algebraic equation:

$$
\frac{d C(t)}{d t}=j \frac{1}{H-h}-\lambda C-\frac{q}{V} C+\frac{q}{2 V} C=0,
$$

where $j=-\left.D \frac{d C(z)}{d z}\right|_{z=h}$ is the diffusion flux of thoron on the top surface of the sample. This system of equations can easily be solved for the thoron concentration measured in the airfilled volume of the sample holder and displayed by RAD7, $C$, which is expressed here as a function of the thickness of the sample:

$$
C(h)=\frac{G}{\lambda \beta+\frac{\gamma\{\lambda(H-h)+q /(2 A)\}}{\tanh (\gamma h)}},
$$

where $\gamma=\sqrt{\lambda \beta / D}\left(\mathrm{~m}^{-1}\right)$ is reciprocating $z_{d}$, the diffusion length of thoron in the sample $(\mathrm{m})$.

\section{Measurements}

For experimental validation of the method we have selected an adobe building material sample (originated from Gyomaendrőd, Békés County, SE-Hungary), and measured the dependence of thoron activity concentration as a function of the sample thickness. The sample has a comparably hard, stable structure which makes it possible to cut and rasp it to 
the appropriate sizes and carry out the measurements. The sample was shaped to the size of the best possible fit in the sample holder with the maximum thickness such that it was still possible to seal the chamber. The gap between the sample sides and the inner wall of the sample holder was filled up with the powder of the sample material to restrict thoron exhalation to the top surface only. In this experiment, sample thickness was reduced from $8.35 \mathrm{~cm}$ to $0.85 \mathrm{~cm}$ in nineteen non-equal steps. Thoron concentration measurements were carried out by the RAD7 detector for at least 4 hours with 15 minutes integrating time intervals, and arithmetic average and standard error (standard deviation of separate measurement results divided by the root of number of measurements) was calculated from these measured values for each sample thickness.

\section{Results and discussion}

Experimental results of thoron concentration measurement as a function of sample thickness is presented on Fig.2. together with the curve of best fit of the model formula. Origin data analysis and graphing software was used to fit the model.

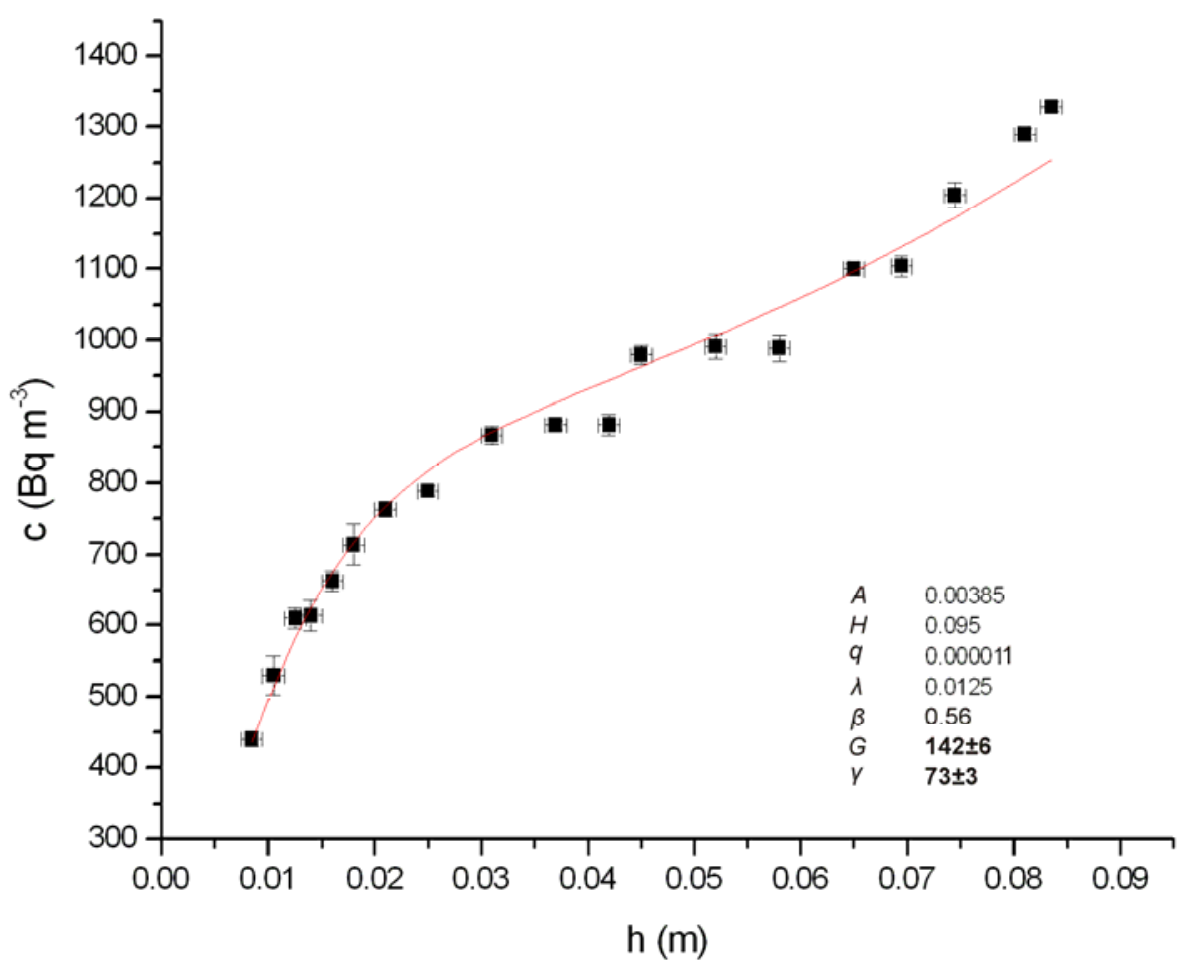

Fig.2.: The measured thoron concentration (c) (quadrates) as a function of the sample thickness $(h)$ in the experiment and the best fit of the formula of the model calculation (line). The fixed parameters and the results of the fit (bold numbers) are presented in the right bottom corner. On the figure we present the fit fixed value of $\beta=0.56$. Note that the $Y$ axis starts at $300 \mathrm{~Bq} \mathrm{m^{-3 }}$. 
We found that the developed formula describes very well the experimental results. It is possible to determine the thoron generation rate, as well as the $\gamma$ parameter for the selected adobe sample via a non-linear curve fitting. We have also tried to fit the parameter $\beta$, however considering it as a free fitting parameter resulted in physically meaningless result. However, we have found that constraining its value between meaningful range $(0<L \varepsilon<$ $\beta<\varepsilon<1$ ) has negligible effect on the fitted values of thoron generation rate and diffusion length. Therefore, it is meaningful to apply a fixed value for $\beta$ in the fitting procedure either by estimating its value or by obtaining it from independent measurements of the porosity and water saturation of the sample.

In the case when the porosity and the water saturation is known we can also make an estimate of the diffusion coefficient and consequently of the diffusion length. The diffusion coefficient can be estimated for example as

$$
D=\varepsilon \beta D_{a} \exp \left(-6 m \varepsilon-6 m^{14 \varepsilon}\right)
$$

where $D_{a} \approx 1.1 \cdot 10^{-5} \mathrm{~m}^{2} \mathrm{~s}^{-1}$ is the diffusion coefficient of thoron in air (Rogers \& Nielson, 1991). In our experiment we have obtained the value of $\gamma=73 \pm 5 \mathrm{~m}^{-1}$ as a result of nonlinear curve fitting. This value can also be accepted as a good estimate for other similar adobe samples. When $\beta$ and $\gamma$ is known, thoron generation rate can be obtained from a single measurement. For routine measurements, when large number of samples has to be measured this is an advantage, because measuring the model predicted curve is difficult and requires a lot of effort and time both in preparing the sample and carrying out the measurements.

The optimum thickness of the sample is in the middle of the height of the sample holder at around $5 \mathrm{~cm}$. Here deviations in sample thickness do not cause high levels of uncertainty (Fig.2.) and it also provides high thoron concentrations, which makes the measurement more precise.

\section{Conclusions}

In this work we have developed and validated a new experimental technique to measure thoron generation rate in building material samples using RAD7 radon-thoron detector. The developed mathematical model of the measurement technique described well the thoron concentration response of RAD7 as a function of the sample thickness. Fitting the parameters of the model to the measurement results, both the generation rate and the diffusion 
length of thoron in the sample material was estimated. For the purpose of large scale measurements making reasonable assumptions we have determined an optimal sample thickness $(5 \mathrm{~cm})$ for estimating the thoron generation rate from a single measurement.

\section{Acknowledgment}

We would like to thank very much the help of local people in the sample collection, Péter Völgyesi in the sample preparation, Dániel Breitner in the discussion of the results and Lithosphere Fluid Research Lab and Department of Atomic Physics, Eötvös University, Budapest, Hungary providing the environment of laboratory work and the RAD7 detector. We are very thankful for the constructive review of the manuscript. $\mathrm{ZsSz}$ is highly thankful for Szabina Török to provide an inspiring environment for finishing the manuscript and for Óskar Halldórsson for many professional discussions and language corrections.

\section{References}

Andersen, C. E., 1992. Entry of soil gas and radon into houses. DK-4000, Roskilde, Denmark: Riso National Laboratory.

Durridge Co., 2013. RAD7 RADON DETECTOR User Manual (Revision 7.2.1.). Boston, 4963.

Németh, C., Tokonami, S., Ishikawa, T., Takahashi, H., Zhuo, W. \& Shimo, M., 2005. Measurements of radon, thoron and their progeny in a dwelling in Gifu prefecture, Japan. Int. Congr. Ser. 1276, 283-284.

Rogers, V. C., \& Nielson, K. K., 1991. Correlations for predicting air permaibilities and 222Rn diffusion coefficients of soils. Health Phys., 367-377.

Sciocchetti, G., Bovi, M., Cotellessa, G., Baldassini, P. G., Battella, C. \& Porcu, I., 1992. Indoor radon and thoron surveys in high radioactivity areas of Italy. Radiat. Prot. Dosim. 45(1-4), 509-514.

Shang, B., Chen, B., Gao, Y., Wang, Y. W., Cui, H. X. \& Li, Z., 2005. Thoron levels in traditional Chinese residential dwellings. Radiat. Environ. Bioph. 44(3), 193-199.

Szabó, Zs., Völgyesi, P., Nagy, H.É., Szabó, Cs., Kis, Z. \& Csorba, O., 2013. Radioactivity of natural and artificial building materials - a comparative study. J. Environ. Radioactiv. 118, 64-74.

Tuccimei, P., Moroni, M., Norcia, D., 2006. Simultaneous determination of 222Rn and 220Rn exhalation rates from building materials used in Central Italy with accumulation chambers 
and a continuous solid state alpha detector: Influence of particle size, humidity and precursors concentration. Appl. Radiat. Isotopes 64, 254-263.

Ujić, P., Čeliković, I., Kandić, A., Žunić, Z., 2008. Standardization and difficulties of the thoron exhalation rate measurements using an accumulation chamber. Radiat. Meas. 43, 1396-1401.

UNSCEAR, 2000. Report of the United Nations Scientific Committee on the Effects of Atomic Radiation to the General Assembly.

Yamada, Y., Tokonami, S., Zhuo, W., Yonehara, H., Ishikawa, T., Furukawa, M., Fukutsu, K., Sun, Q., Hou, C., Zhang, S. \& Akiba, S., 1999. Rn-Tn discriminative measurements and their dose estimates in Chinese loess plateau. Int. Congr. Ser. 1276, 76-80.

Yonehara, H., Tokonami, S., Zhuo, W., Ishikawa, T., Fukutsu, K. \& Yamada, Y., 1999. Thoron in the living environments of Japan. Int. Congr. Ser. 1276, 58-61. 